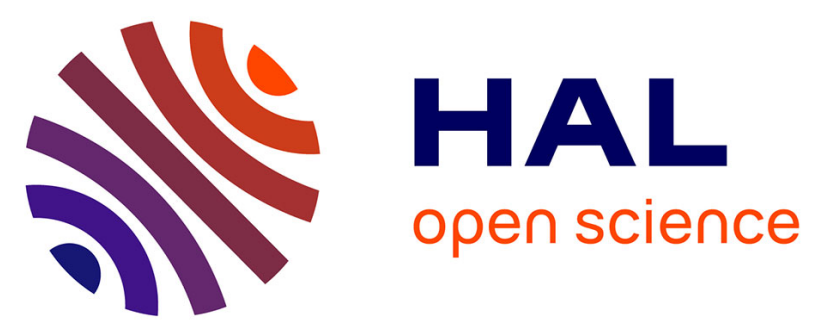

\title{
Hesperidin inhibits ovariectomized-induced osteopenia and shows differential effects on bone mass and strength in young and adult intact rats
}

Marie-Noëlle Horcajada, Veronique Habauzit, Anna Trzeciakiewicz, Christine Morand, Julie Mardon, Patrice Lebecque, Marie-Jeanne M.-J. Davicco, Winnie Chee, Véronique Coxam, Elizabeth Offord

\section{To cite this version:}

Marie-Noëlle Horcajada, Veronique Habauzit, Anna Trzeciakiewicz, Christine Morand, Julie Mardon, et al.. Hesperidin inhibits ovariectomized-induced osteopenia and shows differential effects on bone mass and strength in young and adult intact rats. Journal of Applied Physiology, 2008, 104 (3), pp.648-654. 10.1152/japplphysiol.00441.2007 . hal-02658736

\section{HAL Id: hal-02658736 \\ https://hal.inrae.fr/hal-02658736}

Submitted on 30 May 2020

HAL is a multi-disciplinary open access archive for the deposit and dissemination of scientific research documents, whether they are published or not. The documents may come from teaching and research institutions in France or abroad, or from public or private research centers.
L'archive ouverte pluridisciplinaire HAL, est destinée au dépôt et à la diffusion de documents scientifiques de niveau recherche, publiés ou non, émanant des établissements d'enseignement et de recherche français ou étrangers, des laboratoires publics ou privés. 
M. N. Horcajada, V. Habauzit, A. Trzeciakiewicz, C. Morand, A. Gil-Izquierdo, J. Mardon, P. Lebecque, M. J. Davicco, W. S. S. Chee, V. Coxam and E. Offord

J Appl Physiol 104:648-654, 2008. First published Jan 3, 2008; doi:10.1152/japplphysiol.00441.2007

You might find this additional information useful...

This article cites 37 articles, 8 of which you can access free at:

http://jap.physiology.org/cgi/content/full/104/3/648\#BIBL

This article has been cited by 1 other HighWire hosted article:

Phase II Metabolism of Hesperetin by Individual UDP-Glucuronosyltransferases and Sulfotransferases and Rat and Human Tissue Samples

W. Brand, M. G. Boersma, H. Bik, E. F. Hoek-van den Hil, J. Vervoort, D. Barron, W. Meinl, H. Glatt, G. Williamson, P. J. van Bladeren and I. M. C. M. Rietjens

Drug Metab. Dispos., April 1, 2010; 38 (4): 617-625.

[Abstract] [Full Text] [PDF]

Updated information and services including high-resolution figures, can be found at:

http://jap.physiology.org/cgi/content/full/104/3/648

Additional material and information about Journal of Applied Physiology can be found at: http://www.the-aps.org/publications/jappl

This information is current as of September 8, 2010 .

Journal of Applied Physiology publishes original papers that deal with diverse areas of research in applied physiology, especially those papers emphasizing adaptive and integrative mechanisms. It is published 12 times a year (monthly) by the American

Physiological Society, 9650 Rockville Pike, Bethesda MD 20814-3991. Copyright (C) 2008 by the American Physiological Society.

ISSN: 8750-7587, ESSN: 1522-1601. Visit our website at http://www.the-aps.org/. 


\title{
Hesperidin inhibits ovariectomized-induced osteopenia and shows differential effects on bone mass and strength in young and adult intact rats
}

\author{
M. N. Horcajada, ${ }^{1}$ V. Habauzit, ${ }^{1}$ A. Trzeciakiewicz, ${ }^{1}$ C. Morand, ${ }^{1}$ A. Gil-Izquierdo, ${ }^{2}$ J. Mardon, ${ }^{1}$ \\ P. Lebecque, ${ }^{1}$ M. J. Davicco, ${ }^{1}$ W. S. S. Chee, ${ }^{3}$ V. Coxam, ${ }^{1}$ and E. Offord ${ }^{4}$ \\ ${ }^{1}$ Institut National de la Recherche Agronomique Clermont-Ferrand/Theix, Human Nutrition Unit UMR 1019, St-Genès \\ Champanelle, France; ${ }^{2}$ Centro de Edafología y Biología Aplicada del Segura-Consejo Superior de Investigaciones Científicas \\ (CEBAS-CSIC), Departamento de Ciencia y Tecnología de Alimentos, Espinardo, Spain; ${ }^{3}$ Department of Nutrition \\ and Dietetics, Faculty of Allied Health Sciences, National University of Malaysia, Jalan Raja Muda Abdul Aziz, Kuala \\ Lumpur, Malaysia; ${ }^{4}$ Nestlé Research Center, Nutrition and Health Department, Lausanne, Switzerland
}

Submitted 24 January 2007; accepted in final form 3 January 2008

\begin{abstract}
Horcajada MN, Habauzit V, Trzeciakiewicz A, Morand C, Gil-Izquierdo A, Mardon J, Lebecque P, Davicco MJ, Chee WS, Coxam V, Offord E. Hesperidin inhibits ovariectomized-induced osteopenia and shows differential effects on bone mass and strength in young and adult intact rats. J Appl Physiol 104: 648-654, 2008. First published January 3, 2008; doi:10.1152/japplphysiol.00441.2007.The main aim of this study was to investigate the bone-sparing effect of hesperidin, one of the main flavonoid present in oranges, in two age groups of ovariectomized female rats, compared with their intact controls. Young (3 mo) and adult (6 mo) female Wistar rats were sham operated $(\mathrm{SH})$ or ovariectomized (OVX) and then pair-fed for 90 days a casein-based diet supplemented or not with $0.5 \%$ hesperidin (Hp; $n=10$ /group). In older rats, Hp intake led to a partial inhibition of OVX-induced bone loss, whereas a complete inhibition was obtained in younger animals. At both ages, while plasma osteocalcin concentrations were unchanged, urinary excretion of deoxypyridinoline was reduced by $\mathrm{Hp}$ intake, suggesting that Hp was able to slow down bone resorption. Unexpectedly, in intact young rats, $\mathrm{Hp}$ consumption resulted in a significant increase in bone mineral density (BMD). Indeed, 6-mo-old HpSH rats had a similar BMD to 9-mo-old nontreated $\mathrm{SH}$ adult rats, suggesting an accelerated bone mass gain in the young rats. In contrast, in intact adult rats, Hp did not further increase BMD but did improve their bone strength. The results of this study show a protective effect of $\mathrm{Hp}$ on bone loss in OVX rats of both ages without uterine stimulation and accompanied by a lipid-lowering effect. The unexpected and intriguing findings obtained in intact rats showing improved BMD in young rats and improved femoral load in adult rats merit further investigation. The bone and lipid benefits of hesperidin make it an attractive dietary agent for the management of the health of postmenopausal women.
\end{abstract}

bone growth; bone sparing effect; bone mineral density; polyphenols

A NUMBER OF POPULATION-BASED studies support a positive link between high consumption of fruit and vegetables and improved bone mineral density, an effect postulated to be due to their acid-base buffering capacity, although not yet proven in human intervention studies (26). Experimental rodent studies have shown positive effects on bone with individual polyphenolic components of fruits and vegetables such as quercetin and rutin (a quercetin glycoside) from onions $(15,24)$, resveratrol from red wine (18), and isoflavones from soy (36) that inhibit ovariectomy-induced bone loss in rats by inhibition of

Address for reprint requests and other correspondence: M. N. Horcajada, INRA Clermont-Ferrand/Theix, UNH UMR1019, ASM, 63122 Saint Genès-Champanelle, France (e-mail: horcajad@clermont.inra.fr). bone resorption, independent of the acid-base composition (23, 24). Some human intervention studies with high levels of soy isoflavones (80-90 mg/day) have shown prevention of bone loss in postmenopausal women $(5,30)$, whereas others have not $(4$, 21). Nevertheless, in practice, consumption of soy products is relatively low in Western countries compared with the Asian population, whose average daily intake is $20-40 \mathrm{mg} /$ day (34).

Hesperidin is a monomethoxylated flavanone very abundant in citrus fruits such as oranges (13) and highly consumed in Western countries. For example, in Finland, consumption of hesperidin was estimated to be $28.3 \mathrm{mg} /$ day and contributed to $50 \%$ of total intake of flavonoids (17). The structure of hesperidin corresponds to hesperetin ( $4^{\prime}$-methoxy-3',5,7-trihydroxyflavanone) bound to rutinose (composed of one molecule of rhamnose and one of glucose) in the $C_{7}$ position (14). Hesperetin is absorbed in the colon following release of the rutinose moiety of hesperidin by the gut microflora (20). Human bioavailability studies have shown that flavanones metabolites reached a peak between 5 and $7 \mathrm{~h}$ postingestion $(20,27)$. In the study of Manach et al. (20), the peak plasma concentration of hesperetin was found to be close to $1.3 \mu \mathrm{M}$ following consumption of 1 liter of orange juice, which provided $\sim 450 \mathrm{mg}$ of hesperidin. In the study of Nielsen et al. (27), in which healthy volunteers consumed hesperetin equivalents supplied as fortified orange juice (corresponding to an ingested dose of $192 \pm 30 \mathrm{mg}$ ), the peak plasma concentration of hesperetin was $1.05 \pm 0.25 \mu \mathrm{M}$.

Hesperetin and metabolites have been shown to exert several biological activities in preclinical studies, including antioxidant, anti-inflammatory, analgesic, vasorelaxing, antineoplastic, and lipid-lowering effects $(10,11,22)$. In terms of bone health, hesperidin has been shown to inhibit bone loss in 2-mo-old ovariectomized mice following consumption of $0.5 \%$ hesperidin in the diet (6) and to prevent bone loss in male orchidectomized rats following citrus juice consumption (8).

In the work presented here, we primarily investigated the ability of hesperidin to prevent ovariectomy-induced bone loss in two age groups of female rats (3-6 mo and 6-9 mo). The effect of this citrus flavanone on the sham-operated counterparts was also checked. As a secondary outcome, the lipid modulating effect of hesperidin was measured due to its relevance to postmenopausal women's health.

The costs of publication of this article were defrayed in part by the payment of page charges. The article must therefore be hereby marked "advertisement" in accordance with 18 U.S.C. Section 1734 solely to indicate this fact. 


\section{MATERIALS AND METHODS}

\section{Animals and Diets}

The study was carried out in accordance with the recommendations of the Ethical Committee of the French National Institute for Agronomical Research (Institut National de la Recherche Agronomique) and according to the current legislation on animal experimentation in France (order no. 87-848 modified in 2001). Two groups of 40 young 3-mo-old (266.2 $\pm 1.2 \mathrm{~g})$ and adult 6-mo-old (312.5 $\pm 3.2 \mathrm{~g})$ virgin female Wistar rats were purchased from INRA (Institut National de la Recherche Agronomique, Clermont-Ferrand/Theix, France). Half of the rats in each group were ovariectomized (OVX) and the other half were sham operated $(\mathrm{SH})$ under anesthesia using chloral hydrate (Fluka Chemie, Buchs, Switzerland; $80 \mathrm{~g} / \mathrm{l}$ in saline solution; 0.4 $\mathrm{ml} / 100 \mathrm{~g}$ body wt ip). The animals were housed individually in plastic cages allowing separation and collection of urine and feces at $21^{\circ} \mathrm{C}$ with relative humidity of $55 \%$ and under a 12:12-h light/dark cycle.

After an adaptation period of $1 \mathrm{wk}$ with a semipurified standard diet devoid of any soy proteins (which were replaced by casein; INRA, Jouy-en-Josas, France), the animals were fed the same diet, which contains $0.4 \%$ calcium $(\mathrm{Ca})$ and $0.3 \%$ phosporus $(\mathrm{P})$, but supplemented or not with hesperidin. Hesperidin (from Sigma, L'Isle d'Abeau, Chesnes, France) was added to the diet ( $5 \mathrm{~g} / \mathrm{kg}$ of diet) of 20 sham-operated $(\mathrm{HpSH})$ and 20 ovariectomized rats (HpOVX; Table 1). Diets were prepared every week and stored at $4^{\circ} \mathrm{C}$. To prevent hyperphagia induced by castration, the rats were pair-fed. The animals had free access to water during the entire experiment, and their body weights and food intake were measured weekly. The daily mean consumption within each group and during the whole experimental period (90 days) was $17.9 \pm 0.14 \mathrm{~g}$. Urine of each animal was collected over a 24 -h period on day 0 and the day before slaughtering to measure urinary excretion of deoxypyridinoline (DPD), a marker for bone resorption (32).

Forty-eight hours before death, the body composition was estimated by dual energy X-ray absorptiometry (DEXA; 33). At necropsy, on day 90, blood samples were collected into ice-cooled heparinized plastic tubes containing 200 peptidase inhibitory units of aprotinin (Iniprol, Choay, Paris, France) per milliliter blood, and centrifuged immediately $\left(3,500 \mathrm{~g}\right.$ for $5 \mathrm{~min}$ at $\left.4^{\circ} \mathrm{C}\right)$. Then plasmas were frozen at $-20^{\circ} \mathrm{C}$ until measurements of osteocalcin, a marker of osteoblastic activity (12). Previously, plasma dedicated to hesperetin (the aglycone form of hesperidin) detection was acidified with acetic acid $(0.1 \mathrm{M}, 1 \%)$. Uterine horns were removed and immediately weighed. Femurs were separated from adjacent tissue, cleaned, and used for physical measurements (mechanical testing and bone mineral density).

\section{Physical Analysis}

Whole body composition. Rats were anesthetized by intraperitoneal injection of chloral hydrate $(80 \mathrm{~g} / \mathrm{l}$ in saline solution; $0.4 \mathrm{ml} / 100 \mathrm{~g}$

Table 1. Composition of diets

\begin{tabular}{lcc}
\hline \hline & Control Diet & Hesperidin Diet \\
\hline Casein & 15 & 15 \\
Rapeseed oil & 5 & 5 \\
Wheat starch & 74.0 & 73.5 \\
Calcium phosphate $\left(2 \mathrm{H}_{2} \mathrm{O}\right)$ & 1.68 & 1.68 \\
Sodium chloride & 0.65 & 0.65 \\
Potassium citrate & 1.14 & 1.14 \\
Magnesium sulfate & 0.5 & 0.5 \\
Trace elements mix & 1 & 1 \\
Vitamin mix & 1 & 1 \\
Hesperidin & - & 0.5 \\
\hline
\end{tabular}

Values are shown as $\mathrm{g} / 100 \mathrm{~g}$ dry food. body wt). They were scanned with DEXA using Hologic QDR-4500 A (Hologic, Massy, France). Scans were analyzed, and the percentage of fat and lean masses was measured as previously described (2).

Bone mineral density. Bone mineral density (BMD) was assessed by DEXA, with the Hologic QDR-4500 A X-ray bone densitometer. The total right femur BMD (T-BMD), as well as the BMD of two subregions, one corresponding to the distal femur metaphyseal zone (M-BMD), rich in cancellous bone, and the other to the diaphyseal zone (D-BMD), rich in cortical bone, were determined (28). In each femur scan, distal and proximal metaphyseal regions of interest were positioned at the same distance from the distal and proximal femur extremity, respectively, and with the same height. The region of interest between the two preliminary delimited metaphyseal zones corresponds to the diaphyseal subregion. Results are given in grams per square centimeter.

Femoral mechanical testing. Immediately after collection in $\mathrm{NaCl}$ $(9 \mathrm{~g} / \mathrm{l})$, the length of the right femur and the mean diameter of the diaphysis were measured using a precision caliper (Mitutoyo, Shroppshire, UK). Because of the irregular shape of the femoral diaphysis, the diameter used in the calculation was the mean of the greatest and the smallest diaphysis diameters. Femoral failure load was determined using a three-point bending test. Each bone was secured on the two lower supports (diameter, $4 \mathrm{~mm}$; separation, $20 \mathrm{~mm}$ ) of the anvil of a Universal Testing Machine (Instron 4501; Instron, Canton, MA). An upper crosshead roller (diameter, $6 \mathrm{~mm}$ ) was applied in front of the middle of the shaft of the bone and advanced at $0.5 \mathrm{~mm} / \mathrm{min}$. The load at rupture (Newtons) was automatically determined and recorded by Instron 4501 software. This test method was previously validated by using Plexiglas standard probes (38).

\section{Biochemical Analysis}

Marker of osteoblastic activity. Osteocalcin (OC) in plasma was measured by RIA, using rat ${ }^{125} \mathrm{I}$-labeled OC, goat anti-rat OC antibody, and donkey anti-goat second antibody (Biochemical Technologies kit, Stoughton, MA). The sensitivity was $0.01 \mathrm{nmol} / \mathrm{l}$. The intraand interassay precisions were 6.8 and $8.9 \%$, respectively.

Marker of bone resorption. Deoxypyridinoline (DPD) was measured in urine by competitive RIA (Pyrilinks D kit; Metra Biosystems, Mountain View, CA). The assay requires a rat monoclonal antibody against DPD, which is coated to the inner surface of a polystyrene tube and ${ }^{125}$ I-labeled DPD. In our experimental conditions, the sensitivity was $2 \mathrm{nmol} / \mathrm{l}$, and the intra- and interassay variation was 4 and $6 \%$, respectively. Results are expressed as nanomoles DPD per millimole creatinine to take into account interindividual differences of urine concentration (32). The creatinine assay (kit BioMérieux, Marcy l'Etoile, France) is based on a modified Jaffé's method in which picric acid forms a yellow compound with creatinine presence (7).

Plasma lipids. Plasma total cholesterol and plasma triglycerides concentrations were enzymatically determined using ready-to-use kits purchased from BioMérieux (Marcy l'Etoile, France). After incubation with reagents during $10 \mathrm{~min}$ at room temperature, the intensity of the coloration, which is proportional to the cholesterol or triglycerides content, was measured at $490 \mathrm{~nm}$.

Plasma hesperetin levels. Plasma samples $(180 \mu \mathrm{l})$ were acidified with acetic acid to $\mathrm{pH} 4.9$ and incubated $5 \mathrm{~h}$ at $37^{\circ} \mathrm{C}$ in the presence of 1,000 units of $\beta$-glucuronidase and 45 units of sulphatase (from helix pomatia, Sigma G0876, L'Isle d'Abeau, Chesnes, France). Samples were then mixed with 4 volumes of methanol: $\mathrm{HCl}$ (200 $\mathrm{mmol} / \mathrm{l}$ ) and centrifuged $5 \mathrm{~min}$ at $12,500 \mathrm{~g}$. The supernatant was analyzed by HPLC. HPLC analysis was performed using a system consisting of two pumps (model 580, ESA) for high pressure gradient, a temperature-controlled autosampler (Gilson, Villiers-le-Bel, France), a $150 \times 4.6 \mathrm{~mm}$ Hypersil BDS $\mathrm{C}_{18}-5 \mu$ column (Touzard et Matignon, Les Ulis, France), a thermostatic chamber and eight-channel CoullArray detector (model 5600, Eurosep, Cergy, France). Mobile phases consisted of a $30 \mathrm{mmol} / \mathrm{l} \mathrm{NaH} \mathrm{PO}_{4}$ buffer ( $\mathrm{pH} \mathrm{3}$ ) containing 20\% 
acetonitrile (A) or $40 \%$ acetonitrile (B) (37). Separation was achieved using a gradient elution $\left(35^{\circ} \mathrm{C}, 0.8 \mathrm{ml} / \mathrm{min}\right)$ : $0-3 \mathrm{~min}, 100 \% \mathrm{~A} ; 3-30$ min, linear gradient from $100 \%$ A to $100 \% \mathrm{~B} ; 30-35 \mathrm{~min}, 100 \% \mathrm{~B}$; 35.01-45 $\mathrm{min}, 100 \%$ A. Potentials were set at 50-350-480-550-700 $760-820-850 \mathrm{mV}$ (Pd as reference). Hesperetin was quantified using the sums of height obtained on the electrodes 2,3 and 4, 5, 6, respectively (20).

\section{Statistical Analysis}

Results are expressed as means \pm SE. All data were analyzed using XLSTAT software (Addinsoft, Paris, France). The femoral BMD and biomechanical variables were subjected to a three-way analysis of covariance with body weight as the covariate. Other parameters were analyzed using a three-way ANOVA, testing for any difference among groups. Thus the main effects assessed were age, dietary treatment (Hp or control), and operation (SH or OVX). If a result was found significant $(P<0.05)$, the Student-Newman-Keul's multiple comparisons test was used to determine the specific differences between means. Parametric ANOVA was performed when data were normally distributed with equal variance. If not, nonparametric methods were selected. Thus a Kruskall-Wallis test was first performed. If it indicated a significant difference among groups $(\mathrm{P}<0.05)$, the Mann-Whitney U test (with Bonferroni adjustment to account for multiple comparisons) was used to determine specific differences. The level of significance was set at $P<0.05$ for all statistical tests.

\section{RESULTS}

\section{Uterine Weight and Body Composition}

The mean uterine weight was lower in all the ovariectomized groups compared with sham-operated groups $(P<0.01)$ at both ages of rats. Thus accurate ovariectomy was confirmed by a marked atrophy of uterine horns. In our experimental conditions, uterine weight was unaffected by hesperidin treatment (Table 2).

The animals continued growing throughout the experimental period, and the same pattern of body weight evolution was observed in each age group between day 0 and day 90. At baseline $(D O)$, 6-mo-old rats had significantly higher body weight $(P<0.05)$ than 3 -mo-old animals and this was maintained until the end of the study (D90). Despite pair-feeding, the ovariectomized groups had a significantly $(P<0.01)$ higher body weight than sham-operated groups for both the young and older rats. Hesperidin treatment did not influence the body weights of the animals.

As observed for total body weight, the mean percentage of fat mass measured in the older animals was significantly higher $(P<0.01)$ than in the younger ones and hesperidin consumption had no effect on this parameter (Table 2).

\section{$B M D$}

In the ovariectomized control groups at both ages, ovariectomy induced a significant decrease in total BMD (T-BMD: $-5.2 \%, P<0.05$ in 6 mo old; $-11 \%, P<0.01$ in 9 mo old) as well as in metaphyseal BMD (M-BMD: $-6.2 \%, P<0.05$ in 6 mo old; $-13.3 \%, P<0.01$ in 9 mo old). Diaphyseal BMD was unaffected by ovariectomy in 6-mo-old animals but was significantly decreased in 9-mo-old animals (D-BMD for OVX vs. SH: $-6.6 \%, P<0.01$; Fig. 1$)$.

Total and metaphyseal bone loss was totally inhibited in 6-mo-old ovariectomized rats fed with hesperidin (HpOVX vs. OVX: +14.9\% T-BMD, +10.7\% M-BMD; $P<0.01)$, whereas a more partial inhibition was observed in 9-mo-old rats (HpOVX vs. OVX: +5.6\% T-BMD, +7.6\% M-BMD; $P<0.05$; Fig. 1, $A$ and $B)$. Diaphyseal BMD, although not reduced by ovariectomy in 6-mo-old rats, was nevertheless improved by hesperidin consumption (HpOVX vs. OVX: $+12.7 \% ; P<0.01)$. Moreover, there appears to be a protection by hesperidin of D-BMD loss in the 9-mo-old ovariectomized rats (HpOVX vs. OVX: $+6.9 \% ; P<0.01$; Fig. $1 C$ ).

Unexpectedly, in the sham-operated group of 6-mo-old rats, BMD was significantly improved at all sites (total, metaphyseal, and diaphyseal) by hesperidin consumption ( $\mathrm{HpSH}$ vs. SH: T-BMD + 10.6\%, M-BMD + 11.5\%, D-BMD + $11.8 \%$; $P<0.01$; Fig. 1).

\section{Bone Size and Ultimate Load}

The length $(\mathrm{mm})$ and diameter $(\mathrm{mm})$ of the femur were similar within groups and between ages of animals (Table 2).

Femoral strength was assessed and reported as femoral failure load (Table 2). Ovariectomy significantly decreased this parameter in 9-mo-old control animals $(-12.9 \% ; P<0.05)$ but not in 6-mo-old rats. Consumption of hesperidin totally inhibited the ovariectomy-induced loss of femoral strength in 9-mo-old animals (HpOVX vs. OVX: $+24.3 \% ; P<0.01$ ) and also improved femoral strength in 6-mo-old rats (HpOVX vs. OVX rats: $+9.9 \% ; P<0.05)$.

In the sham-operated groups, hesperidin consumption significantly enhanced femoral strength in 9-mo-old animals (HpSH vs. SH: $+23.6 \% ; P<0.01$ ), whereas no significant increases in femoral strength was observed in intact 6-mo-old animals (Table 2).

\section{Bone Turnover}

On day 90, no differences in plasma OC (ng/ml) levels were observed within 6-mo-old groups with the exception of ovari-

Table 2. Uterine weight, body composition, and femoral ultimate load

\begin{tabular}{|c|c|c|c|c|c|c|c|c|}
\hline & \multicolumn{4}{|c|}{6 mo old } & \multicolumn{4}{|c|}{9 mo old } \\
\hline & $\mathrm{SH}$ & OVX & $\mathrm{HpSH}$ & HpOVX & $\mathrm{SH}$ & OVX & $\mathrm{HpSH}$ & HpOVX \\
\hline Uterus wt, mg & $1031.9 \pm 82.3$ & $146.6 \pm 9.1^{\mathrm{a}}$ & $787 \pm 67.3$ & $238 \pm 22.3^{\mathrm{a}}$ & $607.1 \pm 21.1$ & $108.6 \pm 3.3^{\mathrm{a}}$ & $636.3 \pm 37.2$ & $101.5 \pm 4.5^{\mathrm{a}}$ \\
\hline Body wt, g & $326 \pm 9^{\mathrm{b} *}$ & $363 \pm 7^{a *}$ & $335 \pm 15^{\mathrm{b} *}$ & $406 \pm 12^{\mathrm{a} *}$ & $401 \pm 11^{\mathrm{b}}$ & $414 \pm 12^{\mathrm{a}}$ & $382 \pm 12^{\mathrm{b}}$ & $423 \pm 7^{a}$ \\
\hline Fat mass, \%total body wt & $23.2 \pm 1.1 \dagger$ & $27.7 \pm 1.6 \dagger$ & $25.7 \pm 4.4 \uparrow$ & $27.7 \pm 1.1 \dagger$ & $33.5 \pm 2.2$ & $35.5 \pm 1.6$ & $32.7 \pm 1.9$ & $34.7 \pm 1.6$ \\
\hline Length, mm & $36.22 \pm 0.36$ & $36.35 \pm 0.31$ & $35.97 \pm 0.30$ & $36.46 \pm 0.30$ & $36.87 \pm 0.27$ & $36.67 \pm 0.27$ & $37.25 \pm 0.26$ & $37.30 \pm 0.20$ \\
\hline Diameter, mm & $3.58 \pm 0.06$ & $3.48 \pm 0.05$ & $3.61 \pm 0.04$ & $3.71 \pm 0.05$ & $3.74 \pm 0.07$ & $3.57 \pm 0.05$ & $3.78 \pm 0.06$ & $3.80 \pm 0.06$ \\
\hline Ultimate load, $\mathrm{N}$ & $109.5 \pm 3.3^{*}$ & $102.2 \pm 2.9$ & $106.3 \pm 5.3 \dagger$ & $112.4 \pm 3.4^{\mathrm{h} *}$ & $116.3 \pm 4.3$ & $101.2 \pm 2.9^{\mathrm{cdg}}$ & $143.8 \pm 6.7^{\mathrm{a}}$ & $125.8 \pm 7.4$ \\
\hline
\end{tabular}

Values are means \pm SE. Uterus weight, body weight, fat mass, femoral length, diameter, and ultimate load measured on day 90 (D90) in 6- and 9 mo-old

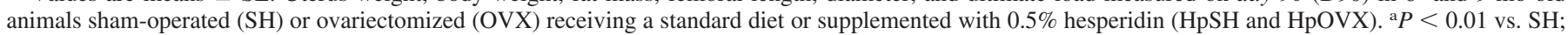
${ }^{\mathrm{b}} P<0.01$ vs. OVX; ${ }^{\mathrm{c}} P<0.05$ vs. SH; ${ }^{\mathrm{d}} P<0.01$ vs. $\mathrm{HpSH} ;{ }^{\mathrm{g}} P<0.01$ vs. HpOVX; ${ }^{\mathrm{h}} P<0.05$ vs. OVX. ${ }^{*} P<0.05$ and $\dagger P<0.01$ vs. 9 -mo-old rats. 


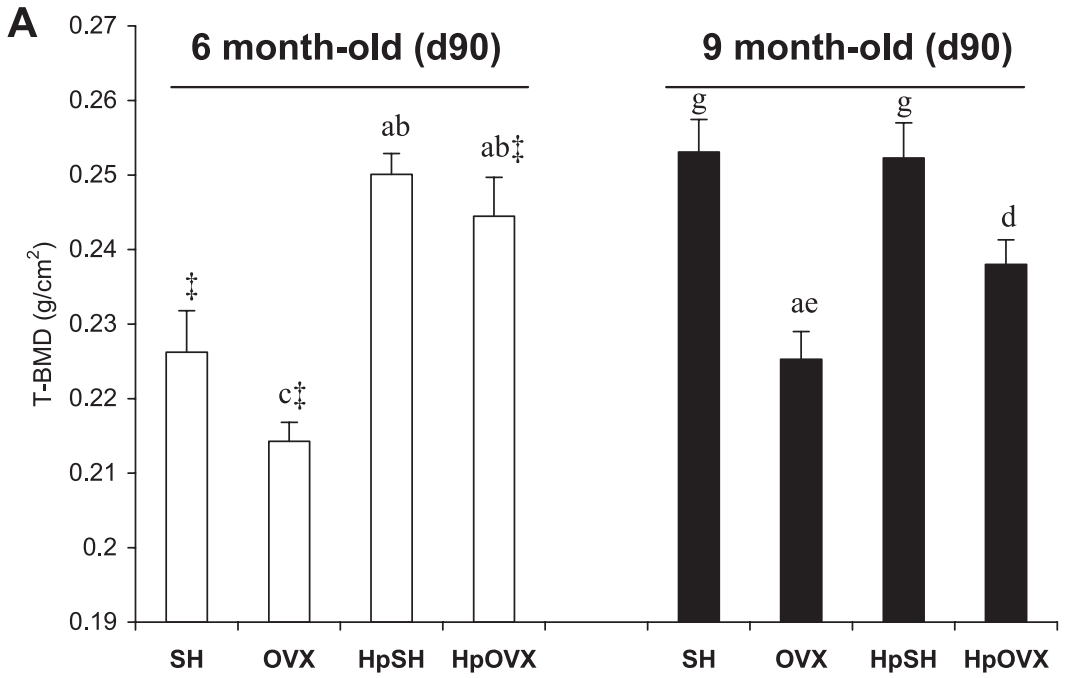

B

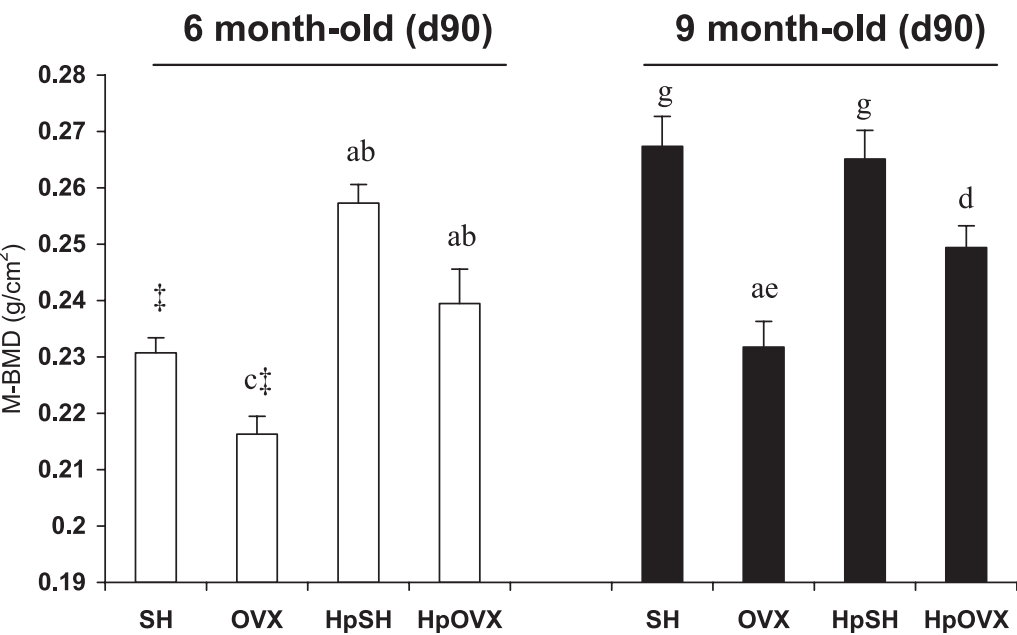

Fig. 1. Total (T-BMD; $A$ ), metaphyseal (M-BMD; $B$ ), and diaphyseal (D-BMD; $C$ ), femoral density $\left(\mathrm{g} / \mathrm{cm}^{2}\right)$ measured on day 90 (d90) in 6- and 9-mo-old animals sham-operated $(\mathrm{SH})$ or ovariectomized (OVX) receiving a standard diet or supplemented with $0.5 \%$ hesperidin (HpSH and HpOVX). Means \pm SE. ${ }^{a} P<0.01$ vs. SH; ${ }^{b} P<0.01$ vs. $\mathrm{OVX}$; ${ }^{\mathrm{c}} P<0.05$ vs. $\mathrm{SH}$ ${ }^{\mathrm{d}} P<0.05$ vs. OVX; ${ }^{\mathrm{e}} P<0.01$ vs. HpSH; ${ }^{\mathrm{f}} P<0.05$ vs. HpSH; ${ }^{\mathrm{g}} P<0.05$ vs. HpOVX; ${ }^{\mathrm{h}} P<0.01$ vs. HpOVX. $\$ P<$ 0.01 vs. 9 -mo-old rats.

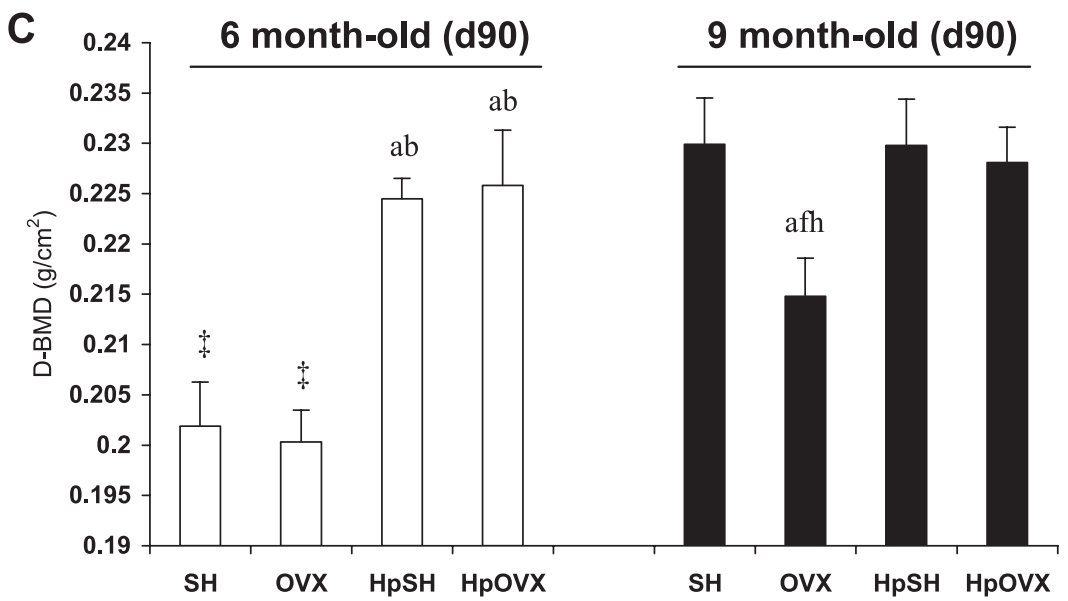

ectomized rats fed hesperidin where a significantly higher concentration was measured compared with sham-operated rats (HpOVX: $38.5 \pm 2.6$ vs. SH: $25.3 \pm 1.9 ; P<0.05$ ). In 9-mo-old animals, ovariectomy enhanced osteocalcin plasma levels in control rats (OVX: $26.6 \pm 2$ vs. SH: $18.9 \pm 1.1 ; P<$ 0.05 ) but hesperidin consumption had no effect on this parameter (Table 3).
Urinary DPD excretion (Table 3) was increased in ovariectomized control rats in both ages $(P<0.01)$. Hesperidin consumption totally inhibited the ovariectomy-induced increase in DPD excretion in 6-mo-old rats (HpOVX vs. OVX: $-38 \% ; P<0.01)$, whereas a partial inhibition was noted in 9-mo-old animals (HpOVX vs. OVX: $-18 \% ; P<0.05$ ). In intact animals, hesperidin consumption led to a reduction of 
Table 3. Plasma osteocalcin, urinary deoxypyridinoline creatinin, total cholesterol, and triglycerides concentrations

\begin{tabular}{|c|c|c|c|c|c|c|c|c|}
\hline & \multicolumn{4}{|c|}{6 mo old } & \multicolumn{4}{|c|}{9 mo old } \\
\hline $\mathrm{OC}, \mathrm{ng} / \mathrm{ml}$ & $25.3 \pm 1.9^{*}$ & $33.1 \pm 2.8^{*}$ & $32.6 \pm 3.7 *$ & $38.5 \pm 2.6^{\mathrm{c} *}$ & $18.9 \pm 1$ & $26.6 \pm 2^{c}$ & $22.5 \pm 2.6$ & $29.9 \pm 1.7^{\mathrm{c}}$ \\
\hline $\mathrm{TC}, \mathrm{g} / \mathrm{l}$ & $0.64 \pm 0.11$ & $0.76 \pm 0.04$ & $0.53 \pm 0.09^{c}$ & $0.64 \pm 0.07^{b}$ & $0.68 \pm 0.12$ & $0.77 \pm 0.08$ & $0.60 \pm 0.11^{\mathrm{c}}$ & $0.69 \pm 0.09^{\mathrm{h}}$ \\
\hline TG, g/l & $2.31 \pm 1.14$ & $1.77 \pm 0.99$ & $1.36 \pm 0.43^{\mathrm{c}}$ & $1.24 \pm 0.37^{\mathrm{h}}$ & $2.64 \pm 0.75$ & $1.67 \pm 0.61$ & $1.47 \pm 0.43^{\mathrm{a}}$ & $1.23 \pm 0.36^{\mathrm{h}}$ \\
\hline
\end{tabular}

Values are means \pm SE. Plasma osteocalcin $(\mathrm{OC}, \mathrm{ng} / \mathrm{ml})$, urinary deoxypyridinoline (DPD, nmol DPD/mmol creatinin), total cholesterol (TC, g/l), and triglycerides (TG, g/l) concentrations measured on day 90 in 6- and 9-mo-old $\mathrm{SH}, \mathrm{OVX}, \mathrm{HpSH}$, and HpOVX animals. ${ }^{\mathrm{a}} P<0.01$ vs. SH; ${ }^{2} P<0.01$ vs. OVX; ${ }^{\mathrm{c}} P<0.05$ vs. $\mathrm{SH} ;{ }^{\text {h }} P<0.05$ vs. OVX. ${ }^{*} P<0.01$ vs. 9 -mo-old rats.

urinary DPD levels in 6-mo-old rats (HpSH vs. $\mathrm{SH}:-16 \%$; $P<0.01$ ) but had no effect in 9-mo-old rats.

\section{Plasma Lipids and Hesperetin Concentrations}

Plasma total cholesterol and triglycerides concentrations (Table 3) were significantly lower in the hesperidin-treated groups compared with the control groups $(P<0.05)$ at both ages.

Finally, the mean plasma concentration of hesperetin was $3.57 \pm 0.68 \mu \mathrm{M}$ in all rats consuming hesperidin, while it was not detectable in plasma of control rats.

\section{DISCUSSION}

In the present work, we investigated the effect of hesperidin, a citrus flavonoid, on bone mineral density and bone metabolism in ovariectomized rats of two ages (3-6 mo and 6-9 mo) compared with their sham-operated intact counterparts.

\section{Characteristics of the Two Ages of Rats}

In the main strains of laboratory rats, sexual maturity is observed between 4 and 9 mo. Thus we can consider both age groups of rats as "mature" regarding estrogen status. According to Schapira et al. (35), building of bone mass occurs throughout the first year of life in Wistar rats with peaks for parameters of bone formation and mineralization (bone protein content, alkaline phosphatase activity, BMD, bone calcium content) mostly attained by age of 8 mo. Thus we can consider that the younger rats $(3-6 \mathrm{mo})$ still have the capacity to acquire bone mass (confirmed by comparison of total BMD of shamoperated rats from 3 to 6 mo, Fig. 1), whereas the older rats (6-9 mo) have achieved their peak bone mass (no difference in total BMD of sham-operated animals from 6 to 9 mo, Fig. 1).

As expected, ovariectomy, validated by uterine weight, induced a significant decrease in BMD in rats of both ages. Similar to what is observed in postmenopausal women, bone turnover was also increased in ovariectomized rats compared with sham-operated ones as indicated by a higher urinary DPD excretion and an increase in plasma levels of osteocalcin (31).

However, comparing the two ages of rats, ovariectomyinduced osteopenia was more severe in the 6- to 9-mo-old rats than in young 3- to 6-mo-old rats, leading to greater loss of trabecular and cortical bone density as well as femoral bone strength and higher bone turnover in accordance with previously reported results in growing (15) and adult (29) animals. Indeed, the younger rats were remarkably insensitive to changes in bone strength by ovariectomy (Table 2). These results may be explained by the fact that the diaphyseal BMD and femoral failure load are related to the cortical compartment that mainly fulfils mechanical functions and is thus less sensitive to estrogen deficiency than cancellous bone, especially in the growing skeleton (31). Hence, the 6- to 9-mo-old adult rats being highly sensitive to ovariectomy-induced osteopenia with effects on BMD, bone resorption biomarkers, and bone strength may indeed be the better model for postmenopausal bone loss (3).

In terms of body composition changes, although ovariectomized rats showed a higher body weight than intact rats, no difference in fat mass content was observed within animals between both age groups by the end of the 90-day feeding period. Moreover, the differences in body weight and fat mass between young and adult rats at the beginning of the experiment remained stable after 3 mo of treatment, suggesting a normal evolution of both body weight and composition.

\section{Effect of Hesperidin on Two Ages of Ovariectomized Rats}

Hesperidin intake led to a complete inhibition of ovariectomy-induced bone loss in the younger rats and a partial inhibition in the older rats, where the osteopenia was more severe. In accordance with the BMD results, ovariectomy induced a higher urinary excretion of DPD, compared with values obtained for sham-operated animals. This effect was inhibited by intake of hesperidin in both age groups of rats (Table 3). These results suggest that hesperidin protects against ovariectomy-induced osteopenia, at least in part due to inhibition of bone resorption. Consistent with these results, a previous study by Chiba et al. (6) showed that in 2-mo-old ovariectomized mice fed $0.5 \%$ hesperidin (same dose as our study) for $2 \mathrm{mo}$, trabecular bone loss and thickness were reduced (compared with sham-operated animals) at the femoral metaphysis accompanied by a reduction in the number of osteoclasts. Similarly, Deyhim et al. (8) showed that citrus juice consumption prevented bone loss in male orchidectomized rats accompanied by a decrease in urinary excretion of hydroxyproline, this being consistent with decreased DPD urinary excretion observed in our study and an overall antiresorptive effect.

In terms of bone strength, the older rats were considerably more sensitive than the younger rats to ovariectomy-induced reduced bone strength and hesperidin was able to reverse this loss of strength (Table 2). In the younger rats, ovariectomy did not significantly affect the cortical bone density, i.e., the diaphyseal BMD, nor the femoral bone strength. Yet, surprisingly, hesperidin intake led to a significant increase in femoral load in the HpOVX animals but not in the HpSH animals (Table 2). Taken together, these results indicate that hesperidin primarily affected BMD in young intact rats with an effect on strength (femoral load) only in ovariectomized animals despite 
the fact that ovariectomy itself did not result in a lower femoral load. Assuming that effects on strength are linked to changes in the bone microarchitecture, then ovariectomy may have fragilized the bones of the younger rats in some way that was not reflected by the femoral load test and that hesperidin intake was able to counteract the effect of ovariectomy such that an improved femoral load was observed in the HpOVX animals.

\section{Effect of Hesperidin in Intact Rats}

Unexpectedly, hesperidin intake led to a significant increase in BMD at all three regions in the sham-operated younger rats (Fig. 1). Furthermore, urinary DPD excretion was significantly reduced by hesperidin consumption in the sham-operated rats, indicating a suppression of bone resorption. Whether hesperidin also stimulated bone metabolism in the sham-operated rats contributing to the improved BMD will require further mechanistic studies. Interestingly, hesperidin intake seemed to accelerate achievement of peak bone mass in the younger animals since 6-mo-old $\mathrm{HpSH}$ animals had the same peak bone mass as 9-mo-old sham-operated rats (Fig. 1). No further increase in BMD was seen between 6- and 9-mo-old HpSH animals (Fig. 1). Indeed, in the older sham-operated rats (which had already achieved peak bone mass), hesperidin did not improve BMD but did improve strength, once again suggesting an effect of hesperidin on the bone microarchitecture. All together, these surprising effects of hesperidin on improved BMD in young intact rats and improved bone strength in older intact rats require further investigation with more detailed biochemical and histomorphometric analyses.

\section{Potential Mode of Action of Hesperidin}

Although the molecular action of hesperetin on bone cells is not yet known, some insights into its mode of action are emerging with respect to its action on modulation of central cellular signaling pathways linked to its antioxidant and antiinflammatory properties. An important study by Kim et al. (16) showed that hesperetin fed to 6- and 24-mo-old rats modulated nuclear factor (NF)-кB in their kidneys, a finding that sheds light on the possible antiresorptive action of hesperetin since NF- $\mathrm{\kappa B}$ is also a key signaling factor in osteoclast proliferation and differentiation (1). Indeed, Kim et al. found that hesperetin suppressed NF- $\mathrm{B}$ signaling through four signal transduction pathways, NIK/IKK, ERK, p38, and JNK and further showed effects on the redox regulating transcription factors Trx/Ref-1. These results would implicate hesperetin as an overall antiaging agent, acting on many tissues, including antiresorptive effects in bone cells.

Concerning the surprising effect we observed on intact rats (improved BMD in younger rats, improved ultimate load in older rats), we can only speculate at this point on a potential stimulation of bone metabolism by hesperidin. One possibility is that there is a relationship with the lipid-lowering effects of hesperidin [see Table 3 for confirmation of lowering of cholesterol and triglycerides levels in our study, in accordance with previous findings $(6,9)]$. It has been shown that statins not only inhibit cholesterol synthesis but also stimulate bone formation via induction of bone morphogenic protein (BMP-2) (25). Whether hesperidin stimulates bone formation in this way remains to be proven. However, in support of an effect on bone formation, we have preliminary data in osteoblast cells show- ing stimulation of alkaline phosphatase activity after 12 days of culture with $4 \mu \mathrm{M}$ of hesperetin (data not shown), indicative of an effect on osteoblast differentiation as previously shown with simvastatin, on MC3T3-E1 cells (19).

\section{Conclusions and Perspectives}

Taken together, the results of this study show a clear protective effect of hesperidin on bone loss and strength in ovariectomized rats of two ages without uterine stimulation. The older rats were more sensitive to the ovariectomy-induced bone loss than the younger ones and the main effect of hesperidin was a slowing down of bone resorption. Surprisingly, hesperidin also stimulated in one hand BMD in young intact rats and in the other hand femoral strength in older intact rats that had probably already achieved their peak bone mass at the start of the feeding period (35). Although the mode of action of hesperidin is not yet elucidated, our results are consistent with an antiresorptive effect of hesperetin possibly via altered NF-кB signaling in osteoclast cells. The lipidlowering effect of hesperidin was confirmed, but whether this has any link to a statin-like effect and associated stimulation of BMP-2 and induced bone formation will require further investigation.

The identification of a non-hormonal dietary agent that may help prevent bone loss and stabilize blood lipids opens up perspectives for the dietary management of women's health in relation to menopause or osteopenia, particularly for those women who are not yet on osteoporotic drug treatment. Furthermore, the broader antiaging potential of hesperidin is of interest to explore for further health benefits. Detailed mechanistic studies will help to direct the primary organ and target population in the future that would benefit most from hesperidin.

\section{REFERENCES}

1. Asagiri M, Takayanagi H. The molecular understanding of osteoclast differentiation. Bone 40: 251-264, 2007.

2. Bertin E, Ruiz JC, Mourot J, Peiniau P, Portha B. Evaluation of dual-energy X-ray absorptiometry for body-composition assessment in rats. J Nutr 128: 1550-1554, 1998.

3. Cai DJ, Zhao YD, Glasier J, Cullen D, Barnes S, Turner CH, Wastney M, Weaver CM. Comparative effect of soy protein, soy isoflavones, and 17 beta-estradiol on bone metabolism in adult ovariectomized rats. $J B$ Mineral Res 20: 828-839, 2005.

4. Cassidy A, Albertazzi P, Nielsen IL, Hall W, Williamson G, Tetens I, Atkins S, Cross H, Manios Y, Wolk A, Steiner C, Branca F. Critical review of health effects of soyabean phyto-oestrogens in post-menopausal women. Proc Nutr Soc 65: 76-92, 2006.

5. Chen YM, Ho SC, Lam SSH, Ho SSS, Woo JLF. Soy isoflavones have a favorable effect on bone loss in Chinese postmenopausal women with lower bone mass: a double-blind, randomized, controlled trial. J Clin Endocrinol Metab 88: 4740-4747, 2003.

6. Chiba H, Uehara M, Wu J, Wang XX, Masuyama R, Suzuki K, Kanazawa K, Ishimi Y. Hesperidin, a citrus flavonoid, inhibits bone loss and decreases serum and hepatic lipids in ovariectomized mice. J Nutr 133: 1892-1897, 2003.

7. Cook JG. Factors influencing the assay of creatinine. Ann Clin Biochem 12: 219-232, 1975 .

8. Deyhim F, Garica K, Lopez E, Gonzalez J, Ino S, Garcia M, Patil BS. Citrus juice modulates bone strength in male senescent rat model of osteoporosis. Nutrition 22: 559-563, 2006.

9. Deyhim F, Lopez E, Gonzalez J, Garcia M, Patil BS. Citrus juice modulates antioxidant enzymes and lipid profiles in orchidectomized rats. J Med Food 9: 422-426, 2006. 
10. Galati EM, Monforte MT, Kirjavainen S, Forestieri AM, Trovato A, Tripodo MM. Biological effects of hesperidin, a citrus flavonoid. (Note I): antiinflammatory and analgesic activity. Farmaco 40: 709-712, 1994

11. Garg A, Garg S, Zaneveld LJ, Singla AK. Chemistry and pharmacology of the Citrus bioflavonoid hesperidin. Phytother Res 15: 655-669, 2001.

12. Garnero P, Delmas PD. [Biochemical markers of bone turnover : clinical usefulness in osteoporosis]. Ann Biol Clin (Paris) 57: 137-148, 1999.

13. Gil-Izquierdo A, Gil MI, Ferreres F, Tomas-Barberan FA. In vitro availability of flavonoids and other phenolics in orange juice. J Agric Food Chem 49: 1035-1041, 2001.

14. Gil-Izquierdo A, Riquelme MT, Porras I, Ferreres F. Effect of the rootstock and interstock grafted in lemon tree (Citrus limon (L.) Burm.) on the flavonoid content of lemon juice. J Agric Food Chem 52: 324-331, 2004.

15. Horcajada-Molteni MN, Crespy V, Coxam V, Davicco MJ, Remesy C, Barlet JP. Rutin inhibits ovariectomy-induced osteopenia in rats. J Bone Miner Res 15: 2251-2258, 2000.

16. Kim JY, Jung KJ, Choi JS, Chung HY. Modulation of the age-related nuclear factor-kappaB (NF-kappaB) pathway by hesperetin. Aging Cell 5: 401-411, 2006.

17. Kumpulainen JT. Intake of flavonoids, phenolic acids and lignans in various populations. 3rd International Conference on Natural Antioxidants and Anticarcinogens in Food, Health and Disease, edited by Voutilainen S and Salonen JT. Helsinki: Kuopion University Publications D. Medical Sciences, 2001, p. 24.

18. Liu ZP, Li WX, Yu B, Huang J, Sun J, Huo JS, Liu CX. Effects of trans-resveratrol from Polygonum cuspidatum on bone loss using the ovariectomized rat model. J Med 8: 14-19, 2005

19. Maeda T, Matsunuma A, Kurahashi I, Yanagawa T, Yoshida H, Horiuchi N. Induction of osteoblast differentiation indices by statins in MC3T3-E1 cells. J Cell Biochem 92: 458-471, 2004.

20. Manach C, Morand C, Gil-Izquierdo A, Bouteloup-Demange C, Remesy C. Bioavailability in humans of the flavanones hesperidin and narirutin after the ingestion of two doses of orange juice. Eur J Clin Nutr 57: 235-242, 2003.

21. Messina M, Ho S, Alekel DL. Skeletal benefits of soy isoflavones: a review of the clinical trial and epidemiologic data. Curr Opin Clin Nutr Metab Care 7: 649-658, 2004.

22. Miyake Y, Yamamoto K, Tsujihara N, Osawa T. Protective effects of lemon flavonoids on oxidative stress in diabetic rats. Lipids 33: 689-695, 1998.

23. Muhlbauer RC, Li F. Effect of vegetables on bone metabolism. Nature 401: 343-344, 1999.
24. Muhlbauer RC, Lozano A, Reinli A. Onion and a mixture of vegetables, salads, and herbs affect bone resorption in the rat by a mechanism independent of their base excess. J Bone Miner Res 17: 1230-1236, 2002.

25. Mundy G, Garrett R, Harris S, Chan J, Chen D, Rossini G, Boyce B, Zhao M, Gutierrez G. Stimulation of bone formation in vitro and in rodents by statins. Science 286: 1946-1949, 1999.

26. New SA. Intake of fruit and vegetables: implications for bone health. Proc Nutr Soc 62: 889-899, 2003.

27. Nielsen IL, Chee WS, Poulsen L, Offord-Cavin E, Rasmussen SE, Frederiksen H, Enslen M, Barron D, Horcajada MN, Williamson G. Bioavailability is improved by enzymatic modification of the citrus flavonoid hesperidin in humans: a randomized, double-blind, crossover trial. J Nutr 136: 404-408, 2006.

28. Pastoureau P, Chomel A, Bonnet J. Specific evaluation of localized bone mass and bone loss in the rat using dual-energy X-ray absorptiometry subregional analysis. Osteoporos Int 5: 143-149, 1995.

29. Picherit C, Chanteranne B, Bennetau-Pelissero C, Davicco MJ, Lebecque P, Barlet JP, Coxam V. Dose-dependent bone-sparing effects of dietary isoflavones in the ovariectomised rat. Br J Nutr 85: 307-316, 2001.

30. Potter SM, Baum JA, Teng HY, Stillman RJ, Shay NF, Erdman JW. Soy protein and isoflavones: their effects on blood lipids and bone density in postmenopausal women. Am J Clin Nutr 68: 1375S-1379S, 1998.

31. Riggs BL, Khosla S, Atkinson EJ, Dunstan CR, Melton LJ 3rd. Evidence that type I osteoporosis results from enhanced responsiveness of bone to estrogen deficiency. Osteoporos Int 14: 728-733, 2003.

32. Robins SP. Biochemical markers for assessing skeletal growth. Eur J Clin Nutr 48, Suppl 1: S199-209, 1994.

33. Rose BS, Flatt WP, Martin RJ, Lewis RD. Whole body composition of rats determined by dual energy X-ray absorptiometry is correlated with chemical analysis. J Nutr 128: 246-250, 1998.

34. Scalbert A, Morand C, Manach C, Remesy C. Absorption and metabolism of polyphenols in the gut and impact on health. Biomed Pharmacother 56: 276-282, 2002.

35. Schapira D, Lotan-Miller R, Barzilai D, Silbermann M. The rat as a model for studies of the aging skeleton. Cells Materials Suppl 1: 181-188, 1991

36. Setchell KDR, Lydeking-Olsen E. Dietary phytoestrogens and their effect on bone: evidence from in vitro and in vivo, human observational, and dietary intervention studies. Am J Clin Nutr 78: 593S-609S, 2003.

37. Skoglund E, Lonnerdal B, Sandberg AS. Inositol phosphates influence iron uptake in Caco-2 cells. J Agric Food Chem 47: 1109-1113, 1999.

38. Turner CH, Burr DB. Basic biomechanical measurements of bone: a tutorial. Bone 14: 595-608, 1993. 